\title{
THE EFFICACY OF MAGNESIUM SULPHATE ON EMERGENCE AGITATION IN ADULTS FOLLOWING NASAL SURGERIES
}

\author{
By

\section{Ayman Hussein Fahmy Kahla, Wael Mohamed El-Mahdi Ibrahim and Ahmed Mahmoud Shehata El-Sayed}

Anesthesiology and Intensive Care Department, Faculty of Medicine, Al-Azhar University

Corresponding author: Ahmed Mahmoud Shehata Elsayed

E-mail: ahmedmshehata4@gmail.com

Phone Number: 01145419913

\begin{abstract}
Background: Emergence agitation (EA), although short-lived, is potentially harmful to the patient and the recovery staff. In the postoperative care unit, an agitated patient requires more nurses to control his abnormal movement and apply restrains that could result in bruises of his extremities.
\end{abstract}

Objectives: The objective of the study was to investigate efficacy of intraoperative magnesium sulphate on prevention of EA in adults undergoing nasal surgeries under sevoflurane anesthesia. Primary outcome of the study was to compare incidence of EA between magnesium and control group. The secondary outcome was to assess pre-operative hemodynamic parameters, sedation scores, emergence time and quality of recovery in both study groups.

Patients and Methods: The present study was conducted in the Al-Hussein University Hospital, following approval from the Ethics Committee of the hospital. This study included 70 adult patients of American Society of Anesthesiologists physical status I and II between 20 and 40 years of age of both sexes, nonsmokers, with BMI less than or equal to 30, posted for nasal surgery under general anesthesia in which nasal packing on each side was used postoperatively. Thorough pre-anesthetic evaluation was done.

Results: In patients undergoing nasal surgeries, intraoperative administration of magnesium decreased the incidence and severity of postoperative agitation, ameliorated postoperative pain and shortened stay in the PACU

Conclusion: The intraoperative administration of magnesium sulphate in patients undergoing nasal surgeries decreased postoperative agitation, pain intensity and pethidine consumption in the early postoperative period. Intraoperative administration of saline did not decrease post operative agitation, pain intensity and pethidine consumption in the early postoperative period.

Keywords: Magnesium Sulphate, Emergence Agitation, Nasal Surgeries

\section{INTRODUCTION}

Emergence agitation (EA) although short-lived is potentially harmful to the patient and the recovery staff (Berhanu, 2018).
In the postoperative care unit, an agitated patient requires more nurses to control his abnormal movement and apply restrains that could result in bruises of his extremities. In the recovery room the agitated patients might remove venous and arterial cannulas, nasal packs and 
oxygen masks leading to bleeding and hypoxia. Emergence agitation is a welldocumented phenomenon in children recovering from sevoflurane anesthesia (Dahmani et al., 2010).

The exact cause for this phenomenon remains to be undetermined. Moreover, many factors play a role in revealing emergence agitation. Several factors have been accused to increase incidence of agitations in adults; pain, hypoxia, type of operation, too rapid emergence from anesthesia, sedatives like benzodiazepines (Suwanpasu et al., 2015).

The incidence of emergence agitation following nasal surgery is relatively high. The exact mechanism is unknown. However, Kim et al. (2013) reported that the occurrence of emergence agitation could be as high as $55.4 \%$, and the presence of nasal pack is likely to be the main trigger of agitation. Elsery (2017) reported an incidence of $68 \%$ following nasal surgery.

There several factors that may increase the incidence of emergence agitation; Male gender, young age, smoking, postoperative pain and premedication with atropine reported a $55 \%$ incidence of EA after nasal surgery. They demonstrated that doxapram administration, pain, and presence of a tracheal tube and or a urinary catheter appear to be the most important causes of postoperative agitation (Rim et al., 2016).

The phenomenon of EA became more apparent with sevoflurane and desflurane (Locatelli et al., 2013). Emergence agitation could be prevented or minimized if the precipitating factors are avoided.
Magnesium sulfate has been reported to decreases emergence agitation following nasal surgery. Hypotensive anesthesia is commonly used with nasal surgery to reduce bleeding and improve the surgical field, so for hypotensive anesthesia. Particular attention should be given to the high-risk group of patients such as young age, males, and smokers. Finally, adequate control of postoperative pain by multimodal analgesic approach could be of help towards a smoother recovery with a calm, alert patient.

The objective of the study was to investigate efficacy of intraoperative magnesium sulphate on prevention of EA in adults undergoing nasal surgeries under sevoflurane anesthesia.

\section{PATIENTS AND METHODS}

This study was a prospective, doubleblinded and controlled randomization study conducted in the Al-Hussein University Hospital, following approval from the Ethics Committee of the hospital.

Following patient informed consent, 70 patients of the following criteria were conducted for this study.

\section{Inclusion criteria:}

1. Both genders.

2. Aged 20-40 years.

3. With American Society of Anesthesiologists (ASA) physical status I or II.

4. Nonsmokers.

5. BMI less than or equal to 30 .

6. Elective nasal surgery under general anesthesia in which nasal packing on each side was used postoperatively. 


\section{Exclusion criteria:}

1. Patients with history of uncontrolled hypertension.

2. Patients with ischemic or valvular heart disease.

3. Patients use MAO inhibitors or adrenergic block.

4. Cognitive impairment.

5. Patients taking antipsychotics.

6. Renal insufficiency or liver impairment.

\section{Duration of Study:}

November 2018 to September 2019.

Patients were randomly divided into two equal groups:

Group (A) received an intial intravenous loading dose of $0.3 \mathrm{ml} / \mathrm{kg}(30 \mathrm{mg} / \mathrm{kg})$ of $10 \%$ solution over $10 \mathrm{~min}$ of magnesium sulphate. This was followed by a continous infusion of $0.1 \mathrm{ml} / \mathrm{kg} \quad(10$ $\mathrm{mg} / \mathrm{kg} / \mathrm{hr}$ ) for the entire duration of surgery.

Group (B) received an equal voulme of saline $0.9 \%$.

All patients were instructed to breath from mouth and were observed by postanesthesia care unit (PACU) nurse who did not participate in data collection.

All patients were intramuscularly premedicated with midazolam $(0.04$ $\mathrm{mg} / \mathrm{kg})$ and atropin $(0.5 \mathrm{mg}) 30 \mathrm{~min}$ before anesthesia induction.

All patient received the same general anesthetic technique by anesthetist who did not participate in data collection. General anesthesia was induced with intravenous fentanyl $(1 \quad ? \mathrm{~g} / \mathrm{kg})$ and propofol $(2.0 \mathrm{mg} / \mathrm{kg})$. Tracheal intubation was facilitated with cisatracurium $(0.15$ $\mathrm{mg} / \mathrm{kg}$ ).

Oropharyngeal packing was performed and positioning of the patients was carried out. Anesthesia was maintained with oxygen/air mixture and sevoflurane.

The operative site was infiltrated by $2 \%$ lidocaine with epinephrine $(1: 200,000)$ for bleeding and pain control. Volume-controlled ventilation will be established with an $8 \mathrm{ml} . \mathrm{kg}$-1 tidal volume and frequency to keep ETCO2 in the range of 4-4.6 $\mathrm{kPa}$. Standard monitoring was maintained throughout the procedure, electrocardiography, noninvasive arterial pressure, peripheral oxygen saturation, capnography, temperature.

Once the surgery was completed, the oropharyngeal pack was removed, and gentle oral suction was carried out. To antagonize the residual neuromuscular blockade at the end of the surgery, neostigmine $(0.05 \mathrm{mg} / \mathrm{kg})$ and atropine $(0.01 \mathrm{mg} / \mathrm{kg})$ were administered. Following these steps, sevoflurane was turned off in the two groups. Emergency was defined as the time interval from 'time 0' until discharge of the patient from the operating room (OR) to the postanesthesia care unit (PACU).

\section{Measured parameters:}

1. Demographic data

2. Agitation level during emergence and at admission in PACU, every $5 \mathrm{~min}$ for the first $15 \mathrm{~min}$ and then every $15 \mathrm{~min}$ until discharged.

3. The ability to cough during emergency.

4. Other complications (desaturation $\mathrm{SpO} 2 \leq 90$, laryngospasm, dizness). 
5. Pain in PACU based on a 11-point numerical rating scale $(0=$ no pain, 1 $3=$ mild pain, $4-6=$ moderate pain, $7-9=$ sever pain, $10=$ worst pain)

6. Post-operative nausea and vomiting (PONV) requiring antiemetics.

7. Discharge from PACU based on modified Aldrete score (Brattain et al., 2015).

8. Patient satisfaction recovery after $24 \mathrm{hr}$ of surgery.

\section{Statistical Analysis:}

Data were collected, revised, coded and entered to the Statistical Package for Social Science (IBM SPSS) version 23. The quantitative data were presented as mean, standard deviations and ranges when parametric and median with inter- quartile range (IQR) when non parametric. Also qualitative variables were presented as number and percentages. The comparison between groups regarding qualitative data was done by using Chisquare test and/or Fisher exact test when the expected count in any cell found less than 5. The comparison between two groups regarding quantitative data and parametric distribution was done by using Independent t-test while with nonparametric distribution was done by using Mann-Whitney test.

The confidence interval was set to $95 \%$ and the margin of error accepted was set to $5 \%$. So, the P-value was considered significant when $\mathrm{P}$-value $>0.05$.

\section{RESULTS}

There was no statistically significant difference found between $\mathrm{MgSO} 4$ and control group regarding demographic data of the studied patients except ASA classification which showed increase in cases with ASA 2 in $\mathrm{MgSO} 4$ group than control group with $\mathrm{p}$-value $=0.041$. There was no statistically significant difference found between $\mathrm{MgSO} 4$ group and saline group regarding duration of surgery with $\mathrm{p}$-value $=0.051$. There was a statistically significant increase in pain score in control group than $\mathrm{MgSO} 4$ group with pvalue $<0.001$ (Table 1). 
Table (1): Comparison between MgSO4 group and control group regarding demographic data and characteristics of studied patients and duration of surgery and pain score

\begin{tabular}{|c|c|c|c|}
\hline \multirow{2}{*}{ Items Groups } & MgSO4 group & Saline group & \multirow{2}{*}{ P-value } \\
\hline & No. $=35$ & No. $=35$ & \\
\hline \multirow{3}{*}{$\begin{array}{l}\text { Age (years) } \\
\text { Mean } \pm \text { SD } \\
\text { Range }\end{array}$} & & & \multirow{3}{*}{0.592} \\
\hline & $28.40 \pm 6.00$ & $27.66 \pm 5.48$ & \\
\hline & $20-40$ & $20-40$ & \\
\hline \multirow{3}{*}{$\begin{array}{l}\text { Sex } \\
\text { Female } \\
\text { Male } \\
\end{array}$} & & & \multirow{3}{*}{0.811} \\
\hline & $18(51.4 \%)$ & $19(54.3 \%)$ & \\
\hline & $17(48.6 \%)$ & $16(45.7 \%)$ & \\
\hline \multirow{3}{*}{$\begin{array}{l}\mathbf{A S A} \\
1 \\
2\end{array}$} & & & \multirow{3}{*}{0.041} \\
\hline & $24(68.6 \%)$ & $31(88.6 \%)$ & \\
\hline & $11(31.4 \%)$ & $4(11.4 \%)$ & \\
\hline \multirow{3}{*}{$\begin{array}{l}\text { BMI } \\
\text { Mean } \pm \text { SD } \\
\text { Range }\end{array}$} & & & \multirow{3}{*}{0.838} \\
\hline & $23.20 \pm 3.16$ & $23.06 \pm 2.51$ & \\
\hline & $18-30$ & $20-28$ & \\
\hline \multirow{3}{*}{$\begin{array}{l}\text { Duration of surgery (hr) } \\
\text { Mean } \pm \text { SD } \\
\text { Range }\end{array}$} & & & \multirow{3}{*}{0.051} \\
\hline & $1.31 \pm 0.38$ & $1.52 \pm 0.47$ & \\
\hline & $1-2$ & $1-2$ & \\
\hline \multirow{3}{*}{$\begin{array}{l}\text { Pain score } \\
\text { Median (IQR) } \\
\text { Range }\end{array}$} & & & \multirow{3}{*}{0.001} \\
\hline & $0(0-1)$ & $7(6-8)$ & \\
\hline & $0-6$ & $4-10$ & \\
\hline \multirow{6}{*}{$\begin{array}{l}\text { Pain } \\
\text { No pain } \\
\text { Mild } \\
\text { Moderate } \\
\text { Severe } \\
\text { Worst }\end{array}$} & & & \multirow{6}{*}{0.001} \\
\hline & $23(65.7 \%)$ & $0(0.0 \%)$ & \\
\hline & $6(17.1 \%)$ & $0(0.0 \%)$ & \\
\hline & $6(17.1 \%)$ & $13(37.1 \%)$ & \\
\hline & $0(0.0 \%)$ & $20(57.1 \%)$ & \\
\hline & $0(0.0 \%)$ & $2(5.7 \%)$ & \\
\hline
\end{tabular}

*: Chi-square test; $\bullet$ : Independent t-test; $\neq$ : Mann-Whitney test

There was no statistically significant difference found between $\mathrm{MgSO} 4$ group and control group regarding agitation at admission in PACU with p-value 0.452, while there was a statistically significant difference found between them regarding agitation at $5 \mathrm{~min}(11.4 \%$ vs $91.4 \%)$ with p-value $<0.001$, at $10 \min (2.9$ vs $91.4 \%)$ with p-value $<0.001$, at $15 \mathrm{~min}(2.9 \%$ vs $94.3 \%$ ) with p-value $<0.001$ and every 15 min thereafter until discharge $(2.9$ vs $91.4 \%$ ) with $\mathrm{p}$-value $<0.001$ (Table 2). 
Table (2): Comparison between MgSO4 group and control group regarding agitation at different times of measurement

\begin{tabular}{|c|c|c|c|c|}
\hline \multirow{2}{*}{\multicolumn{2}{|c|}{$\begin{array}{ll}\text { Agitation level } & \text { Groups } \\
\end{array}$}} & MgSO4 group & Saline group & \multirow{2}{*}{ P-value } \\
\hline & & \multirow{2}{*}{$\begin{array}{l}\text { No. }=35 \\
0(0.0 \%)\end{array}$} & No. $=35$ & \\
\hline \multirow{7}{*}{ At admission in PACU } & Unarousable & & $0(0.0 \%)$ & \multirow{7}{*}{0.452} \\
\hline & Very sedated & $0(0.0 \%)$ & $0(0.0 \%)$ & \\
\hline & Sedated & $0(0.0 \%)$ & $0(0.0 \%)$ & \\
\hline & Calm and cooperative & $0(0.0 \%)$ & $0(0.0 \%)$ & \\
\hline & Agitated & $30(85.7 \%)$ & $32(91.4 \%)$ & \\
\hline & Very agitated & $5(14.3 \%)$ & $3(8.6 \%)$ & \\
\hline & Minimal & $0(0.0 \%)$ & $0(0.0 \%)$ & \\
\hline \multirow{7}{*}{ At 5 min } & Unarousable & $0(0.0 \%)$ & $0(0.0 \%)$ & \multirow{7}{*}{0.001} \\
\hline & Very sedated & $0(0.0 \%)$ & $0(0.0 \%)$ & \\
\hline & Sedated & $0(0.0 \%)$ & $0(0.0 \%)$ & \\
\hline & Calm and cooperative & $31(88.6 \%)$ & $0(0.0 \%)$ & \\
\hline & Agitated & $4(11.4 \%)$ & $32(91.4 \%)$ & \\
\hline & Very agitated & $0(0.0 \%)$ & $3(8.6 \%)$ & \\
\hline & Minimal & $0(0.0 \%)$ & $0(0.0 \%)$ & \\
\hline \multirow{7}{*}{ At 10 min } & Unarousable & $0(0.0 \%)$ & $0(0.0 \%)$ & \multirow{7}{*}{0.001} \\
\hline & Very sedated & $0(0.0 \%)$ & $0(0.0 \%)$ & \\
\hline & Sedated & $31(88.6 \%)$ & $0(0.0 \%)$ & \\
\hline & Calm and cooperative & $3(8.6 \%)$ & $0(0.0 \%)$ & \\
\hline & Agitated & $1(2.9 \%)$ & $32(91.4 \%)$ & \\
\hline & Very agitated & $0(0.0 \%)$ & $3(8.6 \%)$ & \\
\hline & Minimal & $0(0.0 \%)$ & $0(0.0 \%)$ & \\
\hline \multirow{7}{*}{ At 15 min } & Unarousable & $0(0.0 \%)$ & $0(0.0 \%)$ & \multirow{7}{*}{0.001} \\
\hline & Very sedated & $0(0.0 \%)$ & $0(0.0 \%)$ & \\
\hline & Sedated & $34(97.1 \%)$ & $0(0.0 \%)$ & \\
\hline & Calm and cooperative & $0(0.0 \%)$ & $0(0.0 \%)$ & \\
\hline & Agitated & $1(2.9 \%)$ & $33(94.3 \%)$ & \\
\hline & Very agitated & $0(0.0 \%)$ & $2(5.7 \%)$ & \\
\hline & Minimal & $0(0.0 \%)$ & $0(0.0 \%)$ & \\
\hline \multirow{7}{*}{$\begin{array}{l}\text { Every } 15 \text { min } \\
\text { thereafter, } \\
\text { until discharge }\end{array}$} & Unarousable & $0(0.0 \%)$ & $0(0.0 \%)$ & \multirow{7}{*}{0.001} \\
\hline & Very sedated & $5(14.3 \%)$ & $0(0.0 \%)$ & \\
\hline & Sedated & $29(82.9 \%)$ & $0(0.0 \%)$ & \\
\hline & Calm and cooperative & $0(0.0 \%)$ & $0(0.0 \%)$ & \\
\hline & Agitated & $1(2.9 \%)$ & $33(94.3 \%)$ & \\
\hline & Very agitated & $0(0.0 \%)$ & $2(5.7 \%)$ & \\
\hline & Minimal & $0(0.0 \%)$ & $0(0.0 \%)$ & \\
\hline
\end{tabular}

There was no statistically significant difference found between $\mathrm{MgSO} 4$ group and control group regarding the ability to cough during emergence with $\mathrm{p}$-value = 0.074 , while there was a statistically significant difference found between the two groups regarding analgesics used for postoperative pain with a pain score up to 5 with p-value $<0.001$ and also regarding patient's satisfaction with recovery after $24 \mathrm{~h}$ of surgery with p-value $<0.001$ (Table 3). 
Table (3): Comparison between MgSO4 group and control group regarding ability to cough during emergence, other complications and patients satisfaction

\begin{tabular}{|c|c|c|c|c|}
\hline \multirow{2}{*}{\multicolumn{2}{|c|}{$\begin{array}{ll}\text { Items } & \text { Groups } \\
\end{array}$}} & MgSO4 group & \multirow{3}{*}{$\begin{array}{c}\text { Saline group } \\
\text { No. = 35 } \\
33(94.3 \%)\end{array}$} & \multirow[b]{2}{*}{ P-value } \\
\hline & & \multirow{2}{*}{$\begin{array}{c}\text { No. }=\mathbf{3 5} \\
28(80.0 \%)\end{array}$} & & \\
\hline \multirow{4}{*}{$\begin{array}{l}\text { The ability to cough } \\
\text { during } \\
\text { emergence }\end{array}$} & No cough & & & \multirow{4}{*}{0.074} \\
\hline & Single cough & $7(20.0 \%)$ & $2(5.7 \%)$ & \\
\hline & $\begin{array}{l}\text { Persistent cough lasting } \\
\text { less than } 5 \mathrm{~s}\end{array}$ & $0(0.0 \%)$ & $0(0.0 \%)$ & \\
\hline & $\begin{array}{l}\text { Persistent cough lasting } \\
\text { ?5 s or bucking }\end{array}$ & $0(0.0 \%)$ & $0(0.0 \%)$ & \\
\hline Other complication & No & $35(100.0 \%)$ & $35(100.0 \%)$ & \\
\hline \multirow{2}{*}{$\begin{array}{l}\text { Analgesics used for } \\
\text { postoperative } \\
\text { pain with a pain score up } \\
\text { to } 5\end{array}$} & No & $33(94.3 \%)$ & $3(8.6 \%)$ & \multirow[b]{2}{*}{0.001} \\
\hline & Yes & $2(5.7 \%)$ & $32(91.4 \%)$ & \\
\hline $\begin{array}{l}\text { PONV requiring } \\
\text { antiemetics }\end{array}$ & No & $35(100.0 \%)$ & $35(100.0 \%)$ & \\
\hline $\begin{array}{l}\text { Discharge from the } \\
\text { PACU based } \\
\text { on a modified Aldrete } \\
\text { score }\end{array}$ & Yes & $35(100.0 \%)$ & $35(100.0 \%)$ & \\
\hline \multirow{4}{*}{$\begin{array}{l}\text { Patient's satisfaction } \\
\text { with } \\
\text { recovery after } 24 \mathrm{~h} \text { of } \\
\text { surgery }\end{array}$} & Unsatisfied & $0(0.0 \%)$ & $17(48.6 \%)$ & \multirow{4}{*}{0.001} \\
\hline & Neutral & $3(8.6 \%)$ & $18(51.4 \%)$ & \\
\hline & Satisfied & $28(80.0 \%)$ & $0(0.0 \%)$ & \\
\hline & Very satisfied & $4(11.4 \%)$ & $0(0.0 \%)$ & \\
\hline
\end{tabular}

*: Chi-square test

\section{DISCUSSION}

Our results showed that, in patients undergoing nasal surgeries, intraoperative administration of magnesium decreases the incidence and severity of postoperative agitation, ameliorates postoperative pain and shortens stay in the PACU.

Many inter-related postoperative events may provoke agitation, including postoperative pain and hypoxaemia, which are major confounders that may cause or result from agitation. An agitated patient can remove his oxygen mask or injure himself, resulting in more hypoxaemia and pain. In our study, none of the patients had a reduction in $\mathrm{SpO} 2$, excluding hypoxaemia as a confounding factor for agitation. Although pain may be the cause of agitation, it cannot be considered the only cause of postoperative agitation for several reasons. Magnesium itself has antinociceptive properties. In a meta-analysis, including more than 1200 patients, pre-operative magnesium administration was associated with decreased postoperative morphine consumption and pain intensity at rest and on movement. In the current study, magnesium reduced pain in non-agitated patients, indicating that the mechanism of reduction of pain is independent of the reduction of agitation (Peralta-Zamora et al., 2012).

Reported that emergence agitation can occur even after adequate pain treatment or after procedures that are not associated with pain. Postoperative agitation is a well documented phenomenon in children recovering from sevoflurane anesthesia (Dahmani et al., 2010). 
However, adult agitation has been recorded mainly in geriatric patients. In paediatric patients Apan et al. (2010) failed to demonstrate a beneficial effect of magnesium sulphate on agitation after adenotonsillectomy. In contrast, Abdullatif et al. (2013) showed a beneficial effect of magnesium in reducing sevoflurane agitation after the same surgical procedure. The different results between the two reports may be due to methodological issues, i.e. the former used a magnesium infusion before the end of surgery, whereas the latter used a magnesium bolus at the start and an infusion throughout surgery. This highlights the impact of dosing and timing of magnesium administration on outcome.

Postoperative agitation may occur in response to unrelated factors such as pain, medications like benzodiazipines and pethidine, certain surgical procedures, the personal characteristics of the patient, preoperative anxiety and too rapid awakening (Suwanpasu et al., 2015).

No single factor can explain emergence agitation. The high prevalence of postoperative agitation in our study may be due to the nature of the surgery, nasal packs, hypotensive anaesthesia or premedication with atropine. All of our patients were given premedication that included intramuscular atropine $0.5 \mathrm{mg} 1$ $\mathrm{h}$ before anaesthesia, but the dose of $1 \mathrm{mg}$ of intravenous atropine given with neostigmine to reverse residual neuromuscular block might be more likely to influence the incidence of agitation. $Y u$ et al. (2010) reported that $55.4 \%$ of patients were agitated after ENT surgery. Kim et al. (2012) reported a 52\% incidence of agitation after the same surgery. The former used premedication of atropine $0.5 \mathrm{mg}$ and midazolam $0.1 \mathrm{mg} / \mathrm{kg}$ and neostigmine-atropine for reversal, whereas the latter used premedication of glycopyrrolate $0.1 \mathrm{mg}$ and midazolam $0.04 \mathrm{mg} / \mathrm{kg}$, and neostigmine- glycopyrrolate for reversal.

There are some evidences of a neuroprotective effect of magnesium (Bilotta et al., 2013). The mechanism by which magnesium reduces postoperative agitation remains to be determined. Magnesium sulphate is a non-competitive N-methyl-D-aspartate (NMDA) receptor antagonist with antinociceptive effects and also inhibits the entry of calcium ions into cells. Intravenous magnesium sulphate has been shown to suppress the increase in brain lactate concentrations and improves the electroencephalographic changes in response to cerebral ischemia (Kang et al., 2011).

It is possible that magnesium may have decreased agitation by protecting the brain from deleterious effects of prolonged hypotension and other contributing factors. Some types of surgery have been shown to be associated with hypomagnesaemia (Haryalchi et al., 2013).

Magnesium sulphate reduced the length of stay in the PACU and the dose of nitroglycerine necessary to achieve the targeted hypotensive point. This would encourage the routine use of magnesium in hypotensive anaesthesia as a sole agent or combined with other drugs. The results of the current study support the use of magnesium for postoperative agitation in adults. Strengths of the current study are that the trial is a randomised, doubleblinded study with adequate power to 
support the results regarding the primary outcome. Magnesium interacts with neuromuscular blocking agents by reducing acetylcholine release at the motor nerve terminal. When administered preoperatively, magnesium increases the duration of neuromuscular block produced by rocuronium (Czarnetzk et al., 2010).

\section{CONCLUSION}

The intraoperative administration of magnesium sulphate in patients undergoing nasal surgeries decreased postoperative agitation, pain intensity and pethidine consumption in the early postoperative period, while intraoperative administration of saline not decrease postoperative agitation, pain intensity and pethidine consumption in the early postoperative period.

\section{REFERENCES}

1. Abdulatif, M., Ahmed, A., Mukhtar, A. and Badawy, S. (2013): The effect of magnesium sulphate infusion on the incidence and severity of emergence agitation in children undergoing adenotonsillectomy using sevoflurane anaesthesia. Anaesthesia, 68(10): 1045-1052.

2. Berhanu, T. (2018): Incidence of postoperative complications in the major operation room post anesthesia care unit of Tikur Anbessa specialized hospital, 2018 (Doctoral dissertation, Addis Ababa Universty)

3. Bilotta, F., Gelb, A. W., Stazi, E., Titi, L., Paoloni, F. P.and Rosa, G. (2013): Pharmacological perioperative brain neuroprotection: a qualitative review of randomized clinical trials. British journal of anaesthesia, 110(suppl_1): i113-i120.

4. Brattain, A., DInnocenzo, R., Mehra, P. and Rebhun, C. (2015): Standardizing PostAnesthesia Discharge Criteria in an Office Setting. Journal of Oral and Maxillofacial Surgery, 73(9): e47.
5. Czarnetzki, C., Lysakowski, C., Elia, N. and Tramer, M. R. (2010): Time course of rocuronium-induced neuromuscular block after pre-treatment with magnesium sulphate: a randomised study. Acta Anaesthesiologica Scandinavica, 54(3): 299-306.

6. Dahmani, S., Stany, I., Brasher, C., Lejeune, C., Bruneau, B., Wood, C. and Murat, I. J. B. J. A. (2010): Pharmacological prevention of sevofluraneand desflurane-related emergence agitation in children: a meta-analysis of published studies. British journal of anaesthesia, 104(2): 216-223.

7. Elsery, E. H. (2017): Post-operative agitation in adults, factors, possible mechanisms and prevention. Anaesthesiol Clin Sci Res. 1(1): 1-3.

8. Haryalchi, K., Ghanaie, M. M., Yaghoubi, Y., Milani, F.and Faraji, R. (2013): An assessment of changes in the magnesium level during gynecological abdominal surgeries. Journal of Basic and Clinical Reproductive Sciences, 2(2): 110-114.

9. Kang, S. W., Choi, S. K., Park, E., Chae, S. J., Choi, S., Joo, H. J. and Park, H. K. (2011): Neuroprotective effects of magnesium-sulfate on ischemic injury mediated by modulating the release of glutamate and reduced of hyperreperfusion. Brain research, 1371: 121-128.

10. Kim, M. H., Oh, A. Y., Jeon, Y. T., Hwang, J. W. and Do, S. H. (2012): A randomised controlled trial comparing rocuronium priming, magnesium pre-treatment and a combination of the two methods. Anaesthesia, 67(7):748-754.

11. Locatelli, B. G., Ingelmo, P. M., Emre, S., Meroni, V., Minardi, C., Frawley, G. and Sonzogni, V. (2013): Emergence delirium in children: a comparison of sevoflurane and desflurane anesthesia using the Paediatric Anesthesia Emergence Delirium scale. Pediatric anesthesia, 23(4): 301-308.

12. Peralta-Zamora, E. (2012): Strategies to reduce postoperative agitation and delirium in ambulatory anesthesia. Revista Mexicana de Anestesiolog?a, 35(S1): 112-115. 
13. Rim, J. C., Kim, J. A., Hong, J. I., Park, S. Y., Lee, J. H. and Chung, C. J. (2016): Risk factors of emergence agitation after general anesthesia in adult patients. Anesthesia and Pain Medicine, 11(4): 410-416.

14. Suwanpasu, S. and Sattayasomboon, Y. (2015): Hyperactive and hypoactive psychomotor subtypes of delirium in demented and non demented elderly patients with hip fractures: systematic review and meta-analysis. Asian Biomedicine, 9(4): 441453.

15. Yu, D., Chai, W., Sun, X. and Yao, L. (2010): Emergence agitation in adults: risk factors in 2,000 patients. Canadian Journal of Anesthesia/Journal canadien d'anesthésie, 57(9): 843-848. 


\section{فعالية كبريتات الماغنسيوم على التهيج المصاحب للإفاقة لدى الإى التهات البالغين بعد الجر احات الأنفية}

ايمن حسين فهمى كحله، وائل محمد المهدى ابراهيم، أحمد محمود شحاته السيد

قسم التذير والرعاية المركزة، كلية الطب، جامعة الأزهر

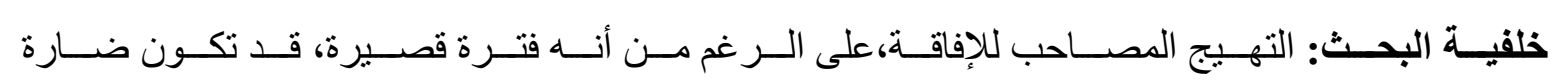

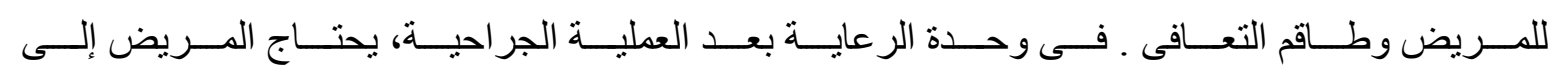

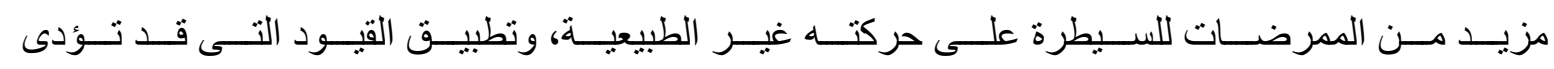
إلى كدمات فى أطر افه.

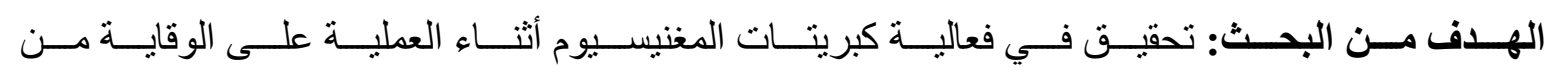

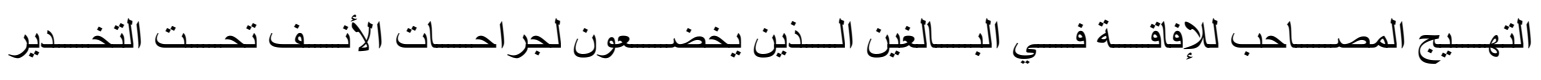

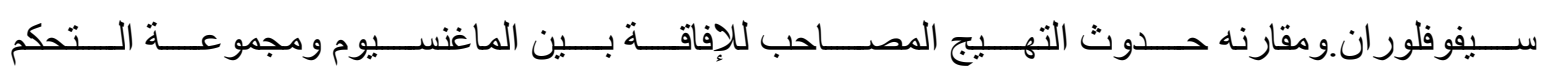

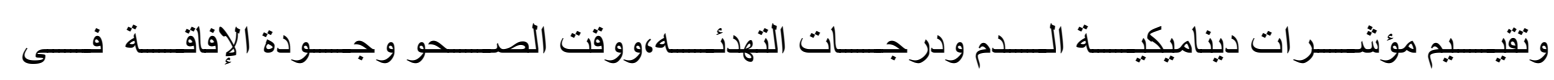
المجموعتين اللتين اقيمت عليهما الدراسة.

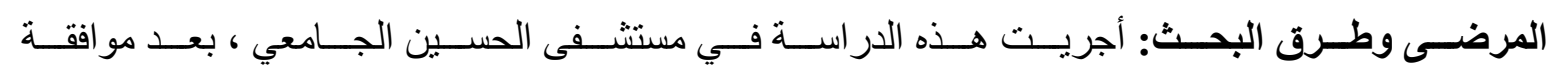

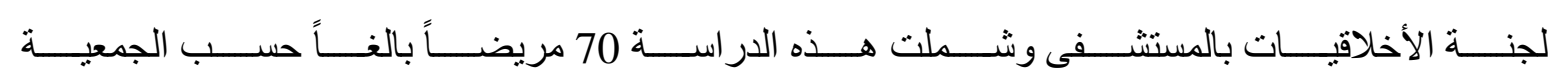

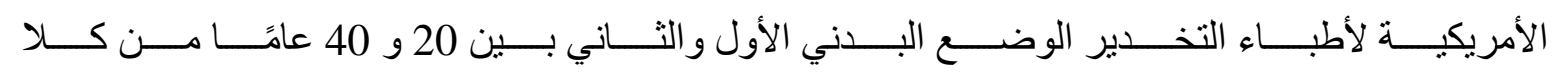

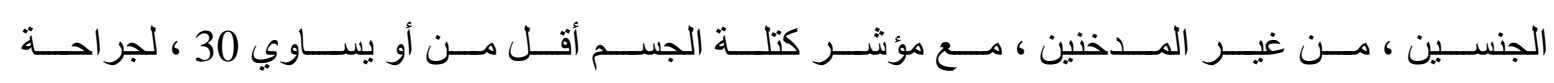
الأنف تحت التخدير وتقييم شامل للتخدير.

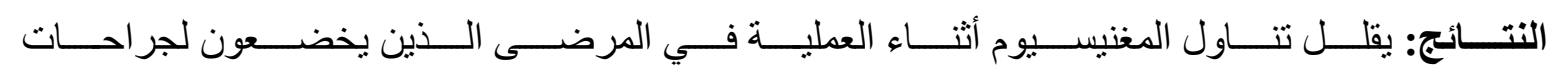

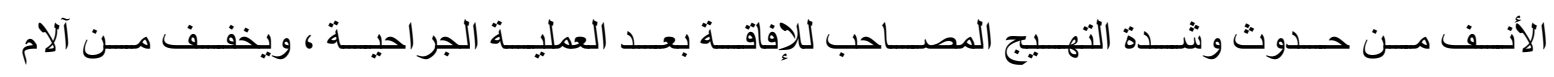
ما بعد الجراحة، ويقصر البقاء في وحدة الرعاية بعد العملية الجراحية.

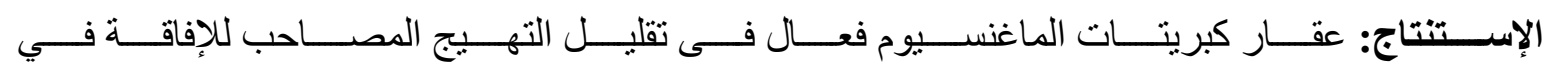

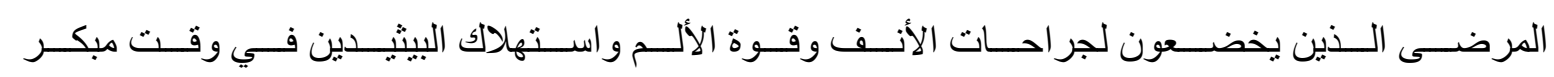

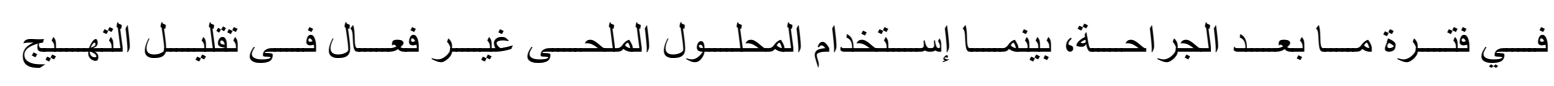

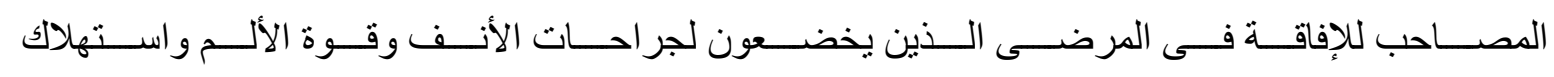
البيثيدين فى وقت مبكر فى فترة ما بعد الجر احة. 